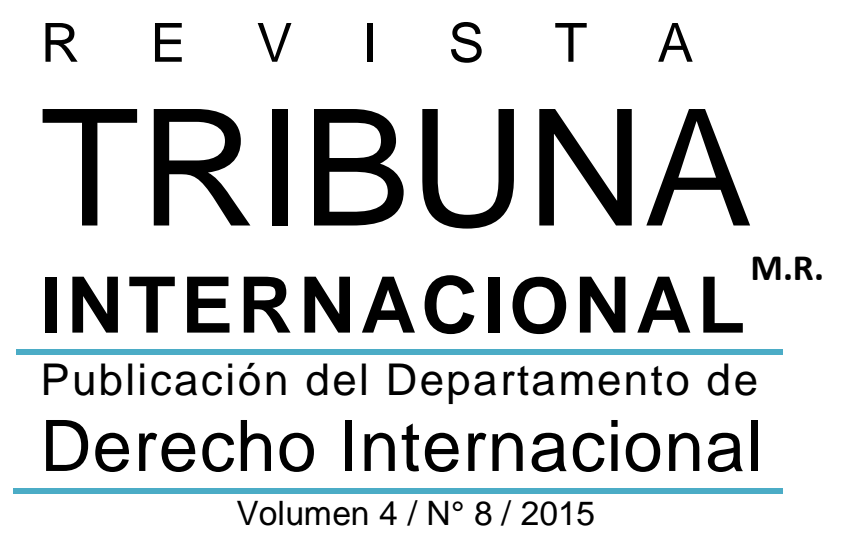

FACULTAD DE DERECHO 


\section{Rector de la Universidad de Chile}

Ennio Vivaldi Véjar

Av. Alameda Libertador Bernardo O'Higgins 1058, Santiago

\section{Representante legal}

Davor Harasic Yaksic

Decano de la Facultad de Derecho

Universidad de Chile

\section{Director Departamento Derecho Internacional}

Edmundo Vargas Carreño

\section{Director (S) Revista Tribuna Internacional}

Mario Arnello Romo

\section{Editor General Revista Tribuna Internacional}

Luis Valentín Ferrada Walker

\section{Comité Editorial}

Íñigo Álvarez Gálvez (Universidad de Chile, Chile)

Gonzalo Aguilar (Universidad de Talca, Chile)

José Carlos Fernández Rosas (Universidad

Complutense de Madrid, España)

Claudio Grossman (American University, EE.UU.)

Mattias Kumm (New York University, EE.UU.)

Hugo Llanos (Universidad Central, Chile)

Cecilia Medina (Universidad Diego Portales, Chile)

Elina Mereminskaya (Universidad de Chile, Chile)

Mónica Pinto (Universidad de Buenos Aires, Argentina)

\section{Fundador de la Revista Tribuna Internacional}

Mario Ramírez Necochea $†$

\section{Revista Tribuna Internacional M.R.}

Publicación del Departamento de Derecho Internacional de la Facultad de Derecho de la Universidad de Chile. Su objetivo es fomentar la reflexión, el debate, el análisis y la comunicación sobre el derecho internacional en forma pluralista y con rigor científico. Se publica cada semestre en los meses de junio y diciembre mediante convocatoria abierta a la publicación de artículos y monografías inéditos, comentarios de jurisprudencia, recensiones y comentarios de libros, en los campos de derecho internacional público y privado, derecho internacional de los derechos humanos y relaciones internacionales, tanto en castellano como inglés.

La Revista Tribuna Internacional fue creada por Decreto Exento No 8.466 de la Rectoría de la Universidad de Chile, de 22 de marzo del 2011

Volumen 4/ No 8 / 2015

www.tribunainternacional.uchile.cl ISSN 0719-482X (versión en línea)

Departamento de Derecho Internacional Facultad de Derecho Universidad de Chile Av. Santa María 076, $4^{\circ}$ piso Providencia, Santiago de Chile

\section{Diseño y producción:}

Facultad de Derecho

Universidad de Chile

Se autoriza la reproducción total o parcial del contenido de la publicación, siempre que se reconozca y cite el/ la/ los/ las autor/a/es/as y la publicación, no se realicen modificaciones a la obra y no se la utilice para fines comerciales. 


\title{
Affaire Khlaifia et autres v. Italie: Estándares del debido proceso aplicados al procedimiento administrativo de migraciones $y$ expulsión ${ }^{1}$
}

\author{
Affaire Khlaifia et autres v. Italie: Standards of due process of law applied to administrative \\ procedure of migration and deportation
}

\section{Bárbara Cortés Cabrera}

barbara.cortes.cabrera@gmail.com

Abogada, Universidad Alberto Hurtado. Postítulo en Derecho Económico Universidad del Desarrollo.

\section{Camilo Jara Villalobos}

cjarav@ug.uchile.cl

Abogado, Universidad de Chile. Diploma en Probidad y Buen Gobierno Pontificia Universidad Católica de Chile.

Resumen: En septiembre de 2015, el Tribunal Europeo de Derechos Humanos resolvió el caso caratulado Affaire Kblaifia et autres v. Italie (Caso Kblaifia y otros c. Italia), relativo al reclamo presentado contra Italia por la retención ilegal, condiciones de detención, e infracciones al debido proceso de migrantes tunecinos que ingresaron ilegalmente al país, a través de embarcaciones ligeras. El fallo es sumamente interesante, pues analiza ciertos estándares jurídicos que deben aplicarse al procedimiento administrativo observado por el Estado, para la expulsión del país de los inmigrantes. El presente trabajo busca identificar los principales criterios establecidos en la sentencia, y compararlos con los estándares establecidos previamente por la doctrina y los otros sistemas de derechos humanos.

Palabras Clave: Inmigración - expulsión - procedimiento administrativo - debido proceso.

Abstract: In September, 2015, the European Court of Human Rights ruled the case Affaire Khlaifia et autres v. Italie (Kblaifia and others v. Italy) relative to the claim filed by Tunisian migrants who entered Italy through light boats, for the unlawful procedure of detention and deportation of the Italian authorities. The judgment is very interesting, because apply the standards originated in the due process of law, to the administrative

Comentario jurisprudencial enviado el 05.10.2015 y aceptado el 13.12.2015. 
Affaire Khlaifia et autres v. Italie: Estándares del debido proceso

Bárbara Cortés Cabrera - Camilo Jara Villalobos

procedure of expulsion of immigrants. This article seeks to identify the main criteria established in the judgment, and compare it with previously standards set by doctrine and other human rights systems.

Keywords: Immigration - expulsion - administrative procedure - due process of law.

\section{Aspectos generales del caso}

Durante los últimos años, hemos sido testigos de cómo los flujos migratorios a nivel mundial han aumentado considerablemente. Si bien el fenómeno de las migraciones masivas no es nuevo, si lo son sus causas, orígenes y destinos; quedando de manifiesto en la crisis migratoria actual que tiene como destino principal los países de la Unión Europea, donde a diario arriban, principalmente del Medio Oriente y África.

La Organización Internacional para las Migraciones, sitúa - al año 2014 - en 214 millones de migrantes internacionales a nivel mundial, correspondiente al 3,1\% de la población total, pudiendo constituir las personas migrantes el quinto país más poblado del mundo 2 . Esta enorme cantidad de personas con frecuencia ve vulnerados sus derechos, principalmente los relativos a las garantías de un debido proceso.

Sentencias de gran trascendencia han logrado exponer el conflicto jurídico que viven las personas al emigrar. Para efecto del presente análisis, abordaremos dicha problemática jurídica desde la perspectiva del debido proceso, a la luz del Derecho Internacional de los Derechos Humanos, particularmente a través de la jurisprudencia del Tribunal Europeo de Derechos Humanos (en adelante "TEDH") en el caso Kblaifia et autres v. Italie ${ }^{3}$ y de la Corte Interamericana de Derechos Humanos (en adelante, "Corte IDH”).

Cuando el 23 de febrero del 2012 el TEDH resolvió el caso Hirsi Jamaa and others v. Italie ${ }^{4}$, logró que el mundo político, intelectual y jurídico internacional observara con atención la sanción a Italia por haber interceptado y devuelto a Libia a un grupo de somalíes y eritreos en 2009. Lo había hecho sin haber analizado antes si esta actuación constituía un riesgo para sus vidas, vulnerando el principio de no devolución, incurriendo en la infracción al principio de prohibición de expulsión colectiva, y no respetando el derecho a un recurso judicial efectivo ante los tribunales en caso de violación de los derechos reconocidos por el Convenio Europeo de Derechos Humanos (en adelante, el "Convenio").

\footnotetext{
Organización Internacional para las Migraciones. Hechos y Cifras, 2014, [en línea] <http://oim.org.mx/hechos-ycifras-2> [consulta: 20 de septiembre del 2015].

TEDH (2015). Petición $\mathrm{N}^{\circ} 16.483 / 12$. Khlaifia et autres $v$. Italie.

4 TEDH (2012). Petición No 27765/09. Hirsi Jamaa and others v. Italie.
} 
Revista Tribuna Internacional

Volumen $4 \cdot \mathrm{N}^{\mathrm{o}} 8 \cdot 2015 \cdot$ pp. 239-253

ISSN 0719-482X (versión en línea)

Sin embargo, nuevamente en septiembre del 2015, Italia fue condenada por el TEDH en el caso caratulado Affaire Khlaifia et autres v. Italie, por la retención ilegal, las condiciones de detención y la expulsión colectiva de migrantes tunecinos que llegaron a la isla italiana de Lampedusa el 2011.

El caso se inició el 17 de septiembre del 2011 con la detención de los señores Khlaifia, Tabal y Sfar por la Guardia Costera italiana, mientras navegaban en dirección al continente Europeo en embarcaciones ligeras. Una vez detenidos, fueron llevados a un Centro de Acogida y Socorro en la isla de Lampedusa. Tras estar detenidos allí por cinco días, fueron trasladados por avión a la ciudad Palermo (Sicilia), y encarcelados por autoridades italianas en barcos anclados en el puerto, los cuales habían sido convertidos en albergues temporales para tales efectos. Finalmente, tras doce días de detención, fueron repatriados a Túnez el 29 de septiembre del mismo año.

El TEDH sostuvo que durante la retención de varios días en el centro de acogida de migrantes de Lampedusa, así como en Palermo, los denunciantes no fueron informados, como prescribe la ley, de las razones jurídicas y factuales de su retención, ni tampoco les fueron comunicados sus derechos, reglas, procedimientos, ni el derecho a presentar recursos contra su detención. Se había producido por lo tanto una vulneración al artículo 13 del Convenio.

Las sentencias del TEDH del 2012 y 2015 resultan paradigmáticas, pues sientan precedentes respecto a los derechos y garantías de migrantes y refugiados. Llama particularmente la atención que ambas sentencias realicen expresa referencia al derecho a un recurso efectivo reconocido en el artículo 13 del Convenio- toda vez que dicho derecho es de naturaleza inminente penal, remontándonos nuevamente a la discusión doctrinal acerca si es posible hacer extensivos los derechos y garantías del debido proceso penal a otras áreas.

Para efecto del presente comentario jurisprudencial resulta interesante poner énfasis en las garantías de debido proceso en procedimientos administrativos en materias migratorias, reconocidos en la jurisprudencia internacional. Para ello, haremos un análisis comparado de las sentencias mencionadas y la jurisprudencia de la Corte Interamericana de Derechos Humanos.

De esta manera, primero abordaremos la discusión sobre el debido proceso administrativo y la aplicación de derechos y garantías del debido proceso penal en él, particularmente respecto de materias migratorias. Luego, ofreceremos un análisis comparado del debido proceso y sus garantías a la luz de la sentencia caratulada Affaire Khlafia et autres v. Italie y de la jurisprudencia de la Corte IDH, particularmente respecto de los siguientes derechos y garantías procedimentales: publicidad, derecho a ser informado de los motivos de la detención, derecho a ser oído, derecho a formular alegaciones y aportar documentos, derecho a un intérprete o traductor, derecho a un recurso efectivo, y derecho a asistencia legal. Finalmente, expondremos algunas conclusiones. 


\section{Debido proceso y debido proceso administrativo}

El debido proceso legal está concebido como el conjunto de garantías que debe considerar un procedimiento judicial, disciplinario o administrativo, con el objeto de resguardar la libertad de las personas y como límite al ejercicio de las actuaciones del poder público, exigiendo su estricta sujeción al derecho y evitando la arbitrariedad. Se exige que las decisiones de los órganos del Estado sean fundadas, razonables, revisables, imparciales, objetivas, y con una participación efectiva de los intervinientes, a través de la presentación de pruebas y en general, de la oportunidad de ser oídos. La doctrina ha señalado que "se puede definir el derecho al debido proceso como aquel que, franqueado el acceso a la jurisdicción, permite que el proceso se desarrolle con todas las garantías esenciales, racionales y justas que contribuyan a un procedimiento equitativo y no arbitrario" 5 .

El debido proceso tiene su origen en el "due process of law" anglosajón, en relación al derecho penal. Si bien sus antecedentes se remontan a la Carta Magna de Inglaterra del año $1215^{6}$, su concepto moderno se origina en la jurisprudencia de la Corte Suprema de Justicia de los Estados Unidos, establecido como un medio para evitar las extralimitaciones de los agentes del Estado en la persecución criminal ${ }^{7}$. De ahí, se extiende hacia las otras ramas del derecho.

Debemos prevenir que, en general, los distintos sistemas de protección de los derechos humanos reconocen la aplicación del estándar del debido proceso a los procedimientos no penales. Sin perjuicio de lo anterior, sobre este último punto no existe una jurisprudencia demasiado extensa ${ }^{8}$.

En el Sistema Universal, el Comité de Derechos Humanos de las Naciones Unidas, a raíz del caso del despido de un funcionario municipal francés, ventilado originalmente ante los tribunales administrativos de ese país, ha resuelto que el debido proceso aplica para casos no penales o civiles en general:

\footnotetext{
GARCíA, Gonzalo y CONTRERAs, Pablo, "El derecho a la tutela judicial y al debido proceso en la jurisprudencia del tribunal constitucional chileno" en Estudios Constitucionales [online], vol. 11, N 2, 2013, pp. 229-282. [en línea]

$<$ http:/ / www.scielo.cl/scielo.php?script=sci_arttext\&pid=S0718-52002013000200007\&lng=en\&nrm=iso\&tlng=en $>$ [consulta: 30 de septiembre del 2015].

6 La Carta Magna del Rey Juan Sin Tierra, establece en su cláusula número 39 que: "Ningún hombre libre podrá ser detenido o encarcelado o privado de sus derechos o de sus bienes, ni puesto fuera de la ley ni desterrado o privado de su rango de cualquier otra forma, ni usaremos de la fuerza contra él ni enviaremos a otros que lo hagan, sino en virtud de sentencia judicial de sus pares o por ley del reino”.

7 Armenta DeU, Teresa. La prueba ilicita (Un estudio comparado). Madrid, Marcial Pons, 2009, pp. 27-29.

8 O’Donnell, Daniel. Derecho Internacional de los Derechos Humanos: Normativa, Jurisprudencia y Doctrina de los Sistemas Universal e Interamericano. $2^{\mathrm{a}}$ edición, Santiago, Alto Comisionado de las Naciones Unidas para los Derechos Humanos, 2007 , p. 361.
} 
Revista Tribuna Internacional

Volumen $4 \cdot \mathrm{N}^{\text {o }} 8 \cdot 2015 \cdot$ pp. 239-253

ISSN 0719-482X (versión en línea)

"El Comité observa a este respecto, que el párrafo mencionado no solo se aplica a materia penal, sino también en los litigios relativos a derechos y obligaciones de carácter civil"’.

El TEDH en oportunidades anteriores también se ha pronunciado en relación a la aplicación de las garantías del debido proceso penal al orden administrativo. Aunque debemos prevenir que lo ha hecho de una manera bastante cauta, en el sentido de señalar que se aplican los derechos del procedimiento penal mutatis mutandi (cambiando lo que debe ser cambiado) al proceso administrativo. En un caso relacionado a la aplicación de sanciones administrativas a médicos belgas señaló que:

"los principios enunciados en el párrafo 2 (art. 6-2) y 3 (a saber los incisos a, b y d), se aplican mutatis mutandis a los procesos disciplinarios a los que se refiere el inciso 1 (art. 6-1) de la misma forma en que se aplican a los casos en que una persona es acusada por una infracción de carácter penal”" 10 .

Por su parte, la Corte IDH ha sido más explícita en el sentido que a los procedimientos administrativos deben aplicarse los estándares del debido proceso. A propósito de un caso sobre responsabilidad de una autoridad, determinada por un juicio político, señaló que:

"la Corte ha dejado establecido que a pesar de que el citado artículo no especifica garantías mínimas en materias que conciernen a la determinación de los derechos y obligaciones de orden civil, laboral, fiscal o de cualquier otro carácter, el elenco de garantías mínimas establecido en el numeral 2 del mismo precepto se aplica también a esos órdenes y, por ende, en ese tipo de materias el individuo tiene también el derecho, en general, al debido proceso que se aplica en materia penal"11.

La Corte IDH se ha pronunciado expresamente en relación a que las actuaciones y procedimientos seguidos ante las autoridades migratorias -en tanto procedimientos administrativos sancionadores-, deben cumplir los estándares generales del debido proceso:

"101. Como se ha demostrado, la Dirección General de Migraciones y Naturalización, entidad de carácter administrativo, fue la autoridad que dictó la 'resolución directoral' que dejó sin efecto el título de nacionalidad del señor Ivcher Bronstein. Por esta razón el Tribunal estima pertinente considerar la aplicación del artículo 8 de la Convención Americana a los hechos del presente caso en el contexto del proceso administrativo.

102. Si bien el artículo 8 de la Convención Americana se titula 'Garantías Judiciales', su aplicación no se limita a los recursos judiciales en sentido estricto, 'sino al conjunto de requisitos que deben observarse en las instancias procesales' a

Comité de Derechos Humanos (1989). Morael v. Francia, párr. 9.3.

10 TEDH (1983). Series A N ${ }^{\circ}$ 58. Albert-Le Compte v. Belgium. párr. 39.

11 CORTE IDH (2001). Serie C No 71. Tribunal Constitucional c. Perú. Fondo, reparaciones y costas. párr. 70. 
efecto de que las personas puedan defenderse adecuadamente ante cualquier acto emanado del Estado que pueda afectar sus derechos"12.

En Chile, la jurisprudencia ha tendido a seguir los lineamientos establecidos por la Corte IDH. Como ejemplo, en el reciente caso denominado "Colusión de Farmacias", conociendo un recurso de reclamación contra una sentencia del Tribunal de Defensa de la Libre Competencia, la Corte Suprema señaló que:

"En efecto, existen principios generales que corresponde tener presente en todo el derecho sancionador $y$, sin duda, en el que regula la libre competencia, tanto en sus aspectos substanciales o materiales, como en los procesales o adjetivos: [...] h.Debido proceso legal. El concepto de 'due process of law', que importa que nadie puede ser condenado a satisfacer una pretensión o sanción, ya sea en materia penal, civil, contravencional, administrativa, disciplinaria o de cualquier naturaleza, si no en virtud de un proceso previo legalmente tramitado"13.

Sobre el contenido exacto que debe tener la noción de debido proceso, en tanto listado de garantías específicas, se trata de un tema complejo. Sin perjuicio de lo anterior, podemos señalar que a modo de enumeración la doctrina entiende que las principales garantías del debido proceso administrativo son las siguientes:

- $\quad$ El oportuno conocimiento de la acción;

- $\quad$ La existencia de un debido emplazamiento;

- El establecimiento de un plazo de investigación;

- La determinación de la oportunidad y número de veces que determinadas medidas pueden decretarse y realizarse;

- $\quad$ La asistencia del abogado defensor;

- $\quad$ La bilateralidad de la audiencia;

- La posibilidad de aportación de pruebas pertinentes; y,

- El derecho a impugnar lo resuelto, mediante recursos ordinarios o especiales ${ }^{14}$.

CORTE IDH (2001). Serie C No 74. Ivcher Bronstein c. Perú. Fondo, reparaciones y costas. párrs. 101-102.

13 CORTE Suprema de Chile (2012), Rol N²578-2012. Fiscalía Nacional Económica contra Farmacias Abumada - Farmacias Cruz, Verde- Farmacias Salco Brand.

14 Arancibia, Tamara, "Análisis Crítico de la Jurisprudencia del Tribunal Constitucional en Materia de Sanciones Administrativas”, Cuadernos del Tribunal Constitucional, N 58, 2014, p. 57. 


\section{Sobre las garantías del debido proceso vulneradas en Affaire Khlafia Autres v. Italie}

\subsection{Derecho a comunicación previa y detallada al inculpado de la acusación formulada}

En el Affaire Khlafia et autres v. Italie, los requirentes denuncian que las autoridades italianas no se contactaron con ellos, mientras permanecían en Italia, violando el artículo 5.2 del Convenio $^{15}$, que al respecto establece que "Toda persona detenida debe ser informada, en el plazo más breve posible y en una lengua que comprenda, de los motivos de su detención y de cualquier acusación formulada contra ella".

Los solicitantes consideran que el deber de información al cual se refiere el artículo en cuestión debe provenir de fuentes de oficiales respecto de la detención, por lo que la comunicación con algunos miembros de ONG's, en temas migratorios, no satisface el deber que impone el artículo 5.2 del Convenio.

En cuanto al TEDH, citando a $V$ an der Leer v. Pays-Bas ${ }^{16}$, sostiene que el párrafo 2 del artículo 5 enuncia una garantía elemental de toda persona detenida, correspondiente a informarle, en un lenguaje sencillo, las razones de su detención y los fundamentos jurídicos y fácticos de su privación de libertad, para que la persona detenida pueda impugnar la legalidad de la misma. Agrega el TEDH, recordando un caso anterior ${ }^{17}$, que los funcionarios a cargo de dicha detención deben proveer de la información referida a la detención en el menor tiempo posible; y que, para determinarlo, se tendrán en cuenta las circunstancias del caso.

Respecto a este punto, el TEDH ha sostenido que el derecho a la información de la manera más pronta debe ser objeto de una interpretación autónoma, que va más allá de medidas penales.

De forma paralela, la jurisprudencia de la Corte IDH respecto del derecho a una comunicación previa y detallada de la acusación, estipulado en el artículo 8.2.b de la Convención Americana de Derechos Humanos, ha señalado que "El Estado debe informar al interesado no solamente de la causa de la acusación, esto es, las acciones u omisiones que se le imputan, sino también las razones que llevan al Estado a formular la imputación, los fundamentos probatorios de ésta y la caracterización legal que se da a esos hechos" ${ }^{\prime 18}$. En otra sentencia, la Corte IDH sostiene que dicha información debe ser "expresa, clara, integral y suficientemente detallada para

\footnotetext{
TEDH (2015). Petición No 16.483/12. Khlaifia et autres v. Italie. párr. 74.

TEDH (1990). Serie A No 170-A, Van der Leer v. Pays-Bas, párr. 142-143.

TEDH (1990). Serie A No 182. Fox, Campbell et Hartley v. Royaume-Uni, párr. 40.

CORTE IDH (2004). Tibi c. Ecuador. Excepciones preliminares, fondo y reparaciones,párr. 187.
} 
Affaire Khlaifia et autres v. Italie: Estándares del debido proceso

Bárbara Cortés Cabrera - Camilo Jara Villalobos

permitir al acusado que ejerza plenamente su derecho a la defensa y muestre al juez su versión de los hechos" ${ }^{\prime 19}$.

\subsection{Derecho a ser oído}

Este derecho se deriva del derecho a un proceso justo, en el cual todas las personas o partes que vayan a ser sujeto de una decisión puedan realizar alegaciones, presentar argumentos y pruebas ante tribunal o autoridad que tomará la decisión. ${ }^{20}$ El concepto proviene del derecho a ser escuchado por la Corte (the day in Court) del derecho anglosajón.

Debemos prevenir que en materia administrativa este derecho también es denominado como el principio de contradictoriedad, y se le define como "el derecho de los interesados en el procedimiento de efectuar sus alegaciones y presentar los antecedentes que estimen pertinentes hasta antes de la dictación del acto terminal”21.

En el Sistema Interamericano, la Corte IDH se ha manifestado específicamente en el sentido de la plena aplicación del derecho a ser oído en los procedimientos administrativos -no solo en aquellos migratorios, o en que esté en juego la libertad o seguridad, sino como un principio general-. En un caso relativo a la prohibición de los ahorristas uruguayos de acceder a sus fondos, y del procedimiento de reclamación ante el Banco Central de ese país, se señaló:

"122. El examen requerido en el presente caso amerita que la Corte precise el alcance del derecho a ser oído establecido en el artículo 8.1 de la Convención Americana. Ese derecho implica, por un lado, un ámbito formal y procesal de asegurar el acceso al órgano competente para que determine el derecho que se reclama en apego a las debidas garantías procesales (tales como la presentación de alegatos y la aportación de prueba). Por otra parte, ese derecho abarca un ámbito de protección material que implica que el Estado garantice que la decisión que se produzca a través del procedimiento satisfaga el fin para el cual fue concebido. Esto último no significa que siempre deba ser acogido sino que se debe garantizar su capacidad para producir el resultado para el que fue concebido. [...]

136. A partir de dichos antecedentes, este Tribunal considera que para garantizar que efectivamente los peticionarios fueran oídos en sus reclamos, a través de este procedimiento especial, era necesario que el órgano encargado de resolver las peticiones pudiera analizar el consentimiento de forma completa"22.

En relación al caso Kblafia, el artículo 6.1 del Convenio se refiere al "derecho [de toda persona] a ser oída equitativa, públicamente y dentro de un plazo razonable por un tribunal

19 CORTE IDH (2009). Barreto Leiva c. Venezuela. Fondo, reparaciones y costas, párr. 28.

20 O’DonnelL, Derecho Internacional de los Derechos Humanos..., op.cit., pp. 368 y 387.

21 Lara, José Luis y Helfmann, Carolina. Repertorio Ley de Procedimiento Administrativo. Santiago, AbeledoPerrot, 2011, p. 96.

22 CORTE IDH (2011). Serie C N 234. Barbani Duarte y otros c. Uruguay. Fondo, reparaciones y costas, párr. 122 y 136. 
Revista Tribuna Internacional

Volumen $4 \cdot \mathrm{N}^{\text {o }} 8 \cdot 2015 \cdot$ pp. $239-253$

ISSN 0719-482X (versión en línea)

independiente e imparcial, establecido por la Ley, que decidirá [...] sobre el fundamento de cualquier acusación en materia penal dirigida contra ella".

En el caso sub lite, el TEDH constató que el procedimiento administrativo de devoluciones y expulsiones de extranjeros en situación irregular, se encontraba regulado en Italia por el Decreto Legislativo $\mathrm{N}^{\circ} 268$ de 1998, el cual no contemplaba expresamente la posibilidad de controvertir o realizar alegaciones en contra de la detención administrativa de los migrantes antes de la emisión del decreto de expulsión ${ }^{23}$. Esto era más grave aún, toda vez que existía un acuerdo cuyo texto no es de carácter público, entre Túnez e Italia, para facilitar la devolución sumaria de los migrantes rescatados en alta $\operatorname{mar}^{24}$.

De este modo, si bien el TEDH alude indirectamente en su sentencia a la inexistencia del derecho a ser oído en la legislación italiana, evita hacer mención expresa del mismo, en cuanto derecho propio del procedimiento administrativo.

\subsection{Derecho a un traductor o intérprete}

El artículo 5.2 del Convenio contempla como garantía el que "toda persona detenida deba ser informada, en el plazo más breve posible, y en una lengua que comprenda, de los motivos de su detención y de cualquier acusación formulada contra ella".

En este sentido, en la sentencia del Affaire Kblafia et autres $v$. Italie, el TEDH ha señalado que la interpretación en el menor plazo posible debe ser autónoma, no acogiendo, de este modo, los argumentos del Estado italiano, consistentes en haber notificado la respectiva orden de expulsión 10 días después de su retención. Asimismo, el TEDH sostuvo que Italia no elaboró ningún documento oficial que proporcionara a los solicitantes las razones de hecho y de derecho de su retención. En consecuencia, la información suministrada no solo era incompleta e inadecuada, sino tampoco fue proporcionada dentro de un plazo razonable

Por tanto, el TEDH concluyó que la información proveída a las personas migrantes no cumplió con lo dispuesto en el artículo 5.2 del Convenio, que ordena comunicar a la persona afectada los motivos de hecho y de derecho de su privación de libertad, arribando a dos conclusiones: 1) Se ha vulnerado el artículo en comento; y 2) la privación de libertad no tiene base legal en la ley italiana.

Por otra parte, en jurisprudencia reciente de la Corte IDH ha manifestado que:

"La Corte observa que los extranjeros detenidos en un medio social y jurídico, diferente de los suyos, y muchas veces con un idioma que desconocen, experimentan una condición de particular vulnerabilidad, que el derecho a la

3 TEDH (2015). Petición No 16.483/12. Khlaifia et autres v. Italie, párr. 27.

24 TEDH (2015). Petición No 16.483/12. Kblaifia et autres $v$. Italie, párr. 71. 
información sobre la asistencia consular, enmarcado en el universo conceptual de los derechos humanos, busca remediar de modo tal de asegurar que la persona extranjera detenida disfrute de un verdadero acceso a la justicia, se beneficie de un debido proceso legal en condiciones de igualdad con quienes no afrontan esas desventajas, y goce de condicione de detención compatibles con el respeto debido a la dignidad de las personas [...] La presencia de condiciones de desigualdad real obliga a adoptar medidas de compensación que contribuyan a reducir o eliminar los obstáculos y deficiencias que impidan o reduzcan la defensa eficaz de los propios intereses" 25 .

\subsection{Derecho a la asistencia legal en procedimientos administrativos de migración}

Tal como señalamos anteriormente en relación a la noción general sobre debido proceso, en prácticamente ningún sistema de protección internacional existen dudas sobre el estándar del derecho a la asistencia legal proporcionada por el Estado para procedimientos criminales.

Sobre el particular, un aspecto no abordado explícitamente por el TEDH en la sentencia del Affaire Khlafia et autres $v$. Italie, es el derecho de los recurrentes a la asistencia legal durante el procedimiento administrativo de devolución o expulsión por parte de Italia, proporcionado por el Estado a través de alguna institución de defensa pública.

En este aspecto, debemos señalar que el Sistema Interamericano es bastante más garantista respecto de los migrantes. Desde larga data, la Corte IDH ha establecido la existencia del derecho a ser asistido por un abogado defensor proporcionado por el Estado para procedimientos administrativos sancionatorios, en especial en aquellos casos en que existe un riesgo cierto de privación de libertad, como sucede precisamente en aquellos de deportación o expulsión. Sobre el particular ha señalado que:

"La Corte ha considerado que, en procedimientos administrativos o judiciales en los cuales se pueda adoptar una decisión que implique la deportación, expulsión o privación de libertad, la prestación de un servicio público gratuito de defensa legal a favor de éstas es necesaria para evitar la vulneración del derecho a las garantías del debido proceso. En efecto, en casos como el presente en que la consecuencia del procedimiento migratorio podía ser una privación de la libertad de carácter punitivo, la asistencia jurídica gratuita se vuelve un imperativo del interés de la justicia"26.

En nuestro país, si bien no se conocen opiniones específicas de la doctrina o jurisprudencia sobre la exigencia de asistencia letrada para procedimientos migratorios, el tema se ha tratado

25 CorTe IDH (2010). Serie C No 218. Vélez. Noor c. Panamá. Excepciones Preliminares. Fondo, reparaciones y costas, párr. 152.

26 CORTE IDH (2010). Serie C No 218. Vélez. Noor c. Panamá. Excepciones Preliminares. Fondo, reparaciones y costas, párr. 146. 
Revista Tribuna Internacional

Volumen $4 \cdot \mathrm{N}^{\text {o }} 8 \cdot 2015 \cdot$ pp. $239-253$

ISSN 0719-482X (versión en línea)

ante el Tribunal Constitucional en relación a los derechos de los administrados en el marco de procedimientos administrativos sancionadores en general. En este sentido se ha reconocido, como parte del debido proceso administrativo, el derecho a contar con la asistencia de un abogado defensor. ${ }^{27}$

\subsection{Derecho a un recurso efectivo}

El derecho a un recurso efectivo consiste en el derecho de toda persona a una garantía judicial específica, destinada a protegerla de manera efectiva frente a la vulneración de sus derechos fundamentales. Éste encuentra un amplio reconocimiento en el derecho internacional.

A este respecto, en la sentencia del Affaire Khlafia et autres $v$. Italie los requirentes arguyeron la vulneración del artículo 13 del Convenio, en relación a los artículos 3 y 5 del mismo y al artículo 4 del Protocolo $N^{o} 4$ de Derechos Humanos. El artículo 13 del Convenio, en torno al cual gira la discusión, estipula que:

"Toda persona cuyos derechos y libertades reconocidos en el presente Convenio hayan sido violados, tiene derecho a la concesión de un recurso efectivo ante una instancia nacional, incluso cuando la violación haya sido cometida por personas que actúen en el ejercicio de sus funciones oficiales".

Los solicitantes sostuvieron que no pudieron ejercer su derecho a un recurso efectivo, fundado en que si bien el decreto de expulsión es susceptible de impugnación dentro de los 60 días siguientes ante el juez de paz, ello no tiene efecto suspensivo. Para los solicitantes, este derecho ya había quedado claramente establecido en la jurisprudencia del TEDH (en particular, caso caratulado Hirsi Jamaa and others $v$. Italie). Además, se señaló que los demandantes nunca tuvieron acceso a las órdenes de expulsión, lo que se demuestra porque nunca firmaron las respectivas notificaciones. Tampoco pudieron tener contacto con sus abogados, ni telefónicamente ni estos pudieron tener acceso a los lugares de detención de sus representados.

Ante ello, el TEDH estuvo por declarar que todas las objeciones planteadas por las partes se encontraban fundadas, para los efectos del artículo 13 del Convenio, debido a que los procedimientos establecidos ante los jueces de paz en contra de los decretos de expulsión, solo pueden ser utilizados para impugnar la legalidad de la repatriación a Túnez, pero no tenían efecto suspensivo. Tampoco existía una acción efectiva contra su deportación de carácter colectivo.

En el mismo sentido que en el Affaire Khlafia et autres v. Italie, en Hirsi Jamma and others v. Italie, el TEDH inquirió si el ordenamiento italiano preveía la existencia de algún recurso que hubieran podido utilizar los extranjeros somalíes y eritreos que fueron localizados en alta mar y

27 AranciBia, “Análisis Crítico...”, op.cit., p. 57. 
devueltos por las autoridades italianas a Libia. Se constató al respecto que pese a la existencia de procedimientos que los requirentes podrían haber interpuestos para evitar su devolución a Libia, ninguno de ellos podría haberse ejercido desde la embarcación que los conducía a Trípoli, perdiendo de esta manera efectividad el derecho al ejercicio de un recurso efectivo.

En paralelo a ello, la Corte IDH, en relación al artículo 25 de la Convención Americana de Derechos Humanos, en numerosas ocasiones se ha manifestado -en casos contenciosos y opiniones consultivas- en relación al alcance de este artículo, el cual estipula:

“1. Toda persona tiene derecho a un recurso sencillo y rápido, o a cualquier otro recurso efectivo ante los jueces o tribunales competentes, que la ampare contra actos que violen sus derechos fundamentales reconocidos por la Constitución, la ley o la presente Convención, aun cuando tal violación sea cometida por personas que actúen en ejercicio de sus funciones oficiales.

2. Los Estados partes se comprometen:

a) a garantizar que la autoridad competente prevista por el sistema legal del Estado decidirá sobre los derechos de toda persona que interponga tal recurso;

b) a desarrollar las posibilidades de recurso judicial, y

c) a garantizar el cumplimiento, por las autoridades competentes, de toda decisión en que se haya estimado procedente el recurso."

Respecto a este derecho, la doctrina lo ha definido como "un derecho autónomo bajo la Convención Americana que obliga a los Estados a garantizar un recurso para la protección de los derechos consagrados en este tratado, en la Constitución y en las leyes internas"28.

Siguiendo la misma línea, la Corte IDH ha sostenido que el derecho a un recurso efectivo “constituye uno de los pilares básicos no sólo de la Convención Americana, sino del propio Estado de Derecho en una sociedad democrática en el sentido de la Convención" ${ }^{\text {"29 }}$, y que para que el Estado cumpla con lo dispuesto en el artículo 25 de la Convención no basta con que los recursos existan formalmente, sino que los mismos deben tener efectividad, es decir, debe brindarse a la persona la posibilidad real de interponer un recurso que sea sencillo y rápido. Cualquier norma o medida que impida o dificulte hacer uso del recurso de que se trata constituye una violación del derecho al acceso a la justicia, bajo la modalidad consagrada en dicho artículo ${ }^{30}$. Asimismo, también se ha manifestado que:

"La salvaguarda de la persona frente al ejercicio arbitrario del poder público es el objetivo primordial de la protección internacional de los derechos humanos. La

\footnotetext{
28 Ministerio Público Fiscal. El Debido Proceso Legal. Análisis desde el Sistema Interamericano y Universal de Derechos Humanos. Buenos Aires, Editorial Eudeba, 2013, tomo I, p. 189.

29 CORTE IDH (2002). Serie C No 97. Cantos c. Argentina. Fondo, reparaciones y costas. párr. 52.

30 CORTE IDH (2002). Serie C No 97. Cantos c. Argentina. Fondo, reparaciones y costas. párr. 52.
} 
Revista Tribuna Internacional

Volumen $4 \cdot \mathrm{N}^{\mathrm{o}} 8 \cdot 2015 \cdot$ pp. 239-253

ISSN 0719-482X (versión en línea)

inexistencia de recursos internos efectivos coloca a las personas en estado de indefensión. El artículo 25.1 de la Convención Americana de Derechos Humanos ha establecido en términos amplios, la obligación a cargo de los estados de ofrecer, a todas las personas sometidas a su jurisdicción, un recurso judicial efectivo contra actos violatorios de sus derechos fundamentales. Dispone, además, que la garantía allí consagrada se aplica no solo respecto de los derechos contenidos en la Convención Interamericana de Derechos Humanos, sino que también de aquellos que estén reconocidos por la Constitución o por la ley"31 (cursivas agregadas).

La sentencia en el Affaire Khlafia et autres v. Italie, viene a reafirmar una línea que el TEDH venía sosteniendo desde hace algunos años, en relación a las garantías del debido proceso en asuntos migratorios. Si bien el Convenio no garantiza como tales el derecho a no ser expulsado o extraditado, ni el derecho ilimitado de entrada y residencia para los no-nacionales, el TEDH ha subsanado estos vacíos mediante sus sentencias, afirmando incluso la obligación de reconocer a toda persona sometida a su jurisdicción los derechos y libertades garantizados por tal tratado $^{32}$. Junto con la obligación de que estos derechos sean concretos y efectivos, diversos fallos imponen a los Estados que se abstengan de expulsar o extraditar a los no-nacionales que corran un riesgo de vulneración de sus derechos en el país de destino. Asimismo, el artículo 13 del Convenio contempla el derecho a un recurso efectivo ante una instancia nacional para todas las personas cuyos derechos reconocidos por el mismo hayan sido vulnerados, incluyendo a los extranjeros demandantes de asilo y a los inmigrantes irregulares. Estos no pueden beneficiarse, en principio, de las garantías procesales del artículo 1 del Protocolo $\mathrm{N}^{\circ} 7$ al Convenio para la Protección de los Derechos Humanos y Libertades Fundamentales, el cual solo tiene aplicación para los extranjeros que residan legalmente en el territorio de un Estado europeo ${ }^{33}$.

En cuanto a la exigencia de un recurso de carácter suspensivo, el TEDH ha reiterado en el Affaire Kblafia et autres v. Italie el mismo criterio utilizado en De Souza Ribeiro v. Francia ${ }^{34}$, al establecer que dicha exigencia rige también para las denuncias en relación al artículo 4 del Protocolo $\mathrm{N}^{\mathrm{o}} 4$, sin que las personas afectadas deban probar que su devolución a un tercer país las expondría a un riesgo real de sufrir tratos contrarios a los artículos 2 y 3 del Convenio. Por tanto, el TEDH concluye en el caso sub lite que el mero hecho de que el recurso interno

31 CORTE IDH (2005). Serie C No 127. Yatama c. Nicaragua. Excepciones Preliminares. Fondo, reparaciones y costas, párr. 167.

32 En Hirsi Jamaa and otbres v. Italie, la Gran Sala del Tribunal estableció que el Convenio se aplica a toda persona que dependa de la jurisdicción de un Estado miembro del Consejo de Europa, incluso si éste ejerce su control sobre ellas fuera del territorio nacional.

33 MORTE, Carmen. "Apuntes sobre Jurisprudencia del TEDH en Materia de Expulsiones Colectivas: El artículo 4 del Protocolo 4 al Convenio” en Abogacia Española, 2015. [en línea] < http://www.abogacia.es/2015/09/25/apuntes-sobrejurisprudencia-del-tedh-en-materia-de-expulsiones-colectivas-el-articulo-4-del-protocolo-4-al-convenio/> [consulta: 05 de octubre del 2015].

34 TEDH (2012). Petición No 22689/07, De Souza Ribeiro v. Francia. 
Affaire Khlaifia et autres v. Italie: Estándares del debido proceso

Bárbara Cortés Cabrera - Camilo Jara Villalobos

carezca de efecto suspensivo es suficiente para constituir una vulneración del artículo 13 del Convenio en relación con el artículo 4 del Protocolo $\mathrm{N}^{\circ} 4{ }^{35}$.

\section{Conclusiones}

Tal como lo hemos señalado, actualmente el mundo enfrenta flujos migratorios sin precedentes. Dentro de esto, el cruce del Mar Mediterráneo acapara gran parte de las miradas del mundo, dada la crisis humanitaria que actualmente se vive.

Si bien históricamente el tratamiento de los asuntos migratorios ha sido potestad de la autoridad administrativa nacional, los casos recientes tratados ante el TEDH demuestran un cambio en el paradigma jurídico-normativo, en relación a la forma en que son tratadas las personas que traspasan las fronteras buscando una mejor calidad de vida.

Específicamente, en el caso Khlafia et autres $v$. Italie el TEDH dispone que todos los migrantes deben tener protección y gozar de las garantías del sistema de protección de los derechos humanos, con independencia de su estatus migratorio, yendo más allá de lo regulado expresamente por el Protocolo $\mathrm{N}^{\circ}$ 7, cuyo texto establece la protección de libertades individuales respecto de extranjeros "con residencia legal".

$\mathrm{Al}$ ampliar el catálogo de derechos a los migrantes que no se encuentren en situación regular, el TEDH está reconociendo el derecho de éstos a ser sujeto de todas las garantías del debido proceso. Esto incluye las garantías mínimas de las personas cuya libertad se ve coartada, tales como el derecho a la comunicación previa y detallada al inculpado de la acusación formulada, a la asistencia jurídica, a un intérprete, a recursos efectivos, a que las resoluciones sean motivadas e, independiente de su situación, derecho a las condiciones de respeto a su dignidad, a la salubridad y seguridad de su internamiento, al traslado al país de origen y a la prohibición de expulsiones masivas.

Si bien se trata de importantes innovaciones a nivel del Sistema Europeo de Derechos Humanos, el fenómeno de la expansión del derecho internacional de los derechos humanos también se ha extendido hasta el Sistema Interamericano de Derechos Humanos. De hecho, la Corte IDH va más allá que el TEDH en lo que se refiere a la observancia de las garantías del debido proceso, tanto en sede penal como en otras áreas, tales como las de competencia civil y administrativa. En este último punto, la Corte IDH ha sido enfática en señalar que las garantías del debido proceso proceden en materias administrativas y migratorias.

35 MORTE, “Apuntes sobre Jurisprudencia del TEDH...”, op.cit. 
Revista Tribuna Internacional

Volumen $4 \cdot \mathrm{N}^{\circ} 8 \cdot 2015 \cdot$ pp. $239-253$

ISSN 0719-482X (versión en línea)

Dado el aumento de los flujos migratorios, en especial en el cruce Mediterráneo por mar, casos como Khlafia et autres $v$. Italie probablemente tenderán a repetirse durante los próximos años. Habrá que estar atento a la próxima jurisprudencia de los tribunales internacionales para ver de qué modo se amplían los derechos de personas migrantes y cómo las políticas migratorias van adecuándose a las nuevas realidades. 